\title{
A review of genetic syndromes associated with hypertrichosis
}

\author{
Vinícius Figueiredo Carneiro ${ }^{1 *}$ (D), Mauro Costa Barbosa² (D), Daniella Reis B. Martelli ${ }^{1,2}$ (1), \\ Paulo Rogério Bonan ${ }^{3}$ (D), Marcos José Burle Aguiar ${ }^{4}$ (D) , Hercílio Martelli Júnior ${ }^{1,2,3}$
}

\section{INTRODUCTION}

Hypertrichosis can be very troublesome for the affected patients and their families. This condition is characterized by an increase in hair growth beyond normal variation in areas that are not predominantly androgen-dependent, independent of age, race, or sex ${ }^{1,2}$. Hypertrichosis is classified according to the age of onset (congenital or acquired), the extent of distribution (generalized or localized), and whether it is isolated or associated with various abnormalities ${ }^{2,3}$. Further classification takes into consideration the type of follicle: lanugo, vellus, or terminal hair. Lanugo follicles are responsible for the growth of the first hairs, which are thin, soft, slightly pigmented, and nonmedullated, produced in the uterus, and are eliminated after birth. Lanugo hypertrichosis has been observed in adults with various forms of hypertrichosis. Vellus follicles are not medullated, thin, and poorly pigmented, and terminal hair is pigmented, medullated, and has a larger diameter compared with other types of hair ${ }^{1,4}$.

The incidence of isolated hypertrichosis is unknown, and it is considered very rare. The incidence increases when it presents itself as a phenotype of several genetic syndromes ${ }^{2}$. Several causes of hypertrichosis have been described, including the use of drugs, infection, neoplasia, genetic diseases, and metabolic or nonendocrine disorders, but it is not caused by an excess of androgens ${ }^{5}$. This condition is often confused with hirsutism; however, the latter refers specifically to the growth of terminal hair in women or children, in androgen-dependent areas, and in places where there is normally no terminal hair, with a typical adult male distribution pattern ${ }^{6}$.
There are several theories for the pathogenesis of hypertrichosis. First, it has been proposed to be caused by the conversion of intermediate or vellus hair to terminal hair, or from changes in the hair growth cycles, with follicles spending more time in the anagen phase and an increase in follicular density ${ }^{1}$. However, the triggers of these mechanisms are still not fully understood.

Hypertrichosis is not only a cutaneous sign but also an underlying rare complex disease that can affect multiple organ systems ${ }^{1-3,7}$ and has previously been related to abnormalities in the head and neck, skeletal, nervous system, intellectual disability (ID), neoplasia, abdominal, genitourinary, cardiovascular, among others. However, there are only a few reviews in the literature. The aim of this study was to offer an overall survey of hypertrichosis-associated genetic diseases described in the literature and provide a summary of its clinical presentation.

\section{METHODS}

A search was performed from June 2020 to October 2020 in the online electronic database Online Mendelian Inheritance in Man (OMIM, https://www.omim.org), with associations of the terms "hypertrichosis" or "hirsutism." Nondependent disturbances to androgen metabolism or syndromes with overlapping features were included as hypertrichosis. Additional searches were performed in the electronic databases PubMed (https:// pubmed.ncbi.nlm.nih.gov) and Orphanet (https://www.orpha. net/consor/cgi-bin/index.php) to complement the search for scientific articles, in the English language.

The clinical features of each disturbance were organized into categories by one collaborator, as provided in OMIM, and

\footnotetext{
${ }^{1}$ Universidade Estadual de Montes Claros, Primary Care Postgraduate Program - Montes Claros (MG), Brazil.

2Universidade Estadual de Montes Claros, Oral Pathology and Oral Medicine, - Montes Claros (MG), Brazil.

${ }^{3}$ Universidade Federal de Alfenas, Center for Rehabilitation of Craniofacial Anomalies, Dental School - Alfenas (MG), Brazil.

${ }^{4}$ Hospital das Clínicas da Universidade Federal de Minas Gerais, Special Genetics Service - Belo Horizonte (MG), Brazil.

*Corresponding author: vinicius.carneiro@unimontes.br

Conflicts of interest: the authors declare there are no conflicts of interest. Funding: none.

Received on July 13, 2021. Accepted on August 10, 2021.
} 
features of the head and neck, inheritance, skeletal, cardiovascular, ID, nervous system, neoplasia, genitourinary, abdominal, endocrine, respiratory, dental anomalies, and phenotypic and genetic characteristics were also evaluated. The data were entered into Excel for statistical analyses. The study collected public domain data, thus dispensing with the approval of the Ethics and Research Committee.

\section{RESULTS}

A total of 274 entries were found in OMIM. In 33 entries, both terms hypertrichosis and hirsutism were referring to the same disturbance. Notably, 121 genetic conditions associated with hypertrichosis were included in the research, as described in Chart 1. Description of genes and disturbances caused by hyperandrogenism or related conditions, such as polycystic ovarian syndrome, hyperprolactinemia, hyperthyroidism, congenital adrenal hyperplasia, androgen-secreting tumors, among others, were excluded. However, more than one OMIM entry can refer to the same syndrome. Disturbances with overlapping syndromes were also included. A few disturbances were not found in OMIM, but were found in PubMed (i.e., dysraphism, nevoid hypertrichosis, polythelia pilosa, primary multifocal hypertrichosis, and segmental odontomaxillary dysplasia). The distribution of the frequency of clinical involvement categories is described in Table 1.

The main inheritance pattern observed was autosomal recessive (44.62\%). Nevertheless, some disturbances can occur with a mixed pattern. Autosomal dominance was observed in $36.36 \%$, and other or unknown inheritance patterns were observed in $20.66 \%$ of genetic entities. The most affected categories observed were the head and neck features $(80.16 \%)$, skeletal (78.51\%), and the nervous system $(73.55 \%)$.

Other highlighted categories were ID (52.06\%), abdomen (42.97\%), genitourinary (39.66\%), dental anomalies (32.23\%), cardiovascular (32.23\%), respiratory (25.61\%), and early death, until childhood (18.18\%). Malignancies were of another concern, observed in $8.26 \%$ of cases, as described in Table 2, and endocrinopathies were identified in $14.04 \%$ of disturbances.

\section{DISCUSSION}

There has been a growing recognition that rare diseases are relevant medical and social problems ${ }^{8-10}$. In this study, 121 genetic disturbances associated with hypertrichosis were identified. The first documented case of hypertrichosis in the scientific literature was the case of Petruz Gonzales, born in the Canary Islands archipelago in 1556, at the Ambras Castle 2 . Other cases later became famous, including those of circus exhibitionists, such as the case of Julia Pastrana, a Mexican dancer of indigenous origin, and the Russian Theodoro Petrov ${ }^{11,12}$. Although more than 300 new Mendelian phenotypes are added to the OMIM each year ${ }^{13}$, only a few cases of hypertrichosis-associated genetic disturbances have been reported.

The prevalence of congenital generalized hypertrichosis is very rare ${ }^{2}$. Nevertheless, no universally accepted definition for rare diseases has yet been established ${ }^{10,14}$. According to the World Health Organization (WHO) and the criterion adopted by the Ministry of Health of Brazil, a rare disease is a disease whose prevalence affects less than $65 / 100,000$ individuals or 1.3/2,000 individuals ${ }^{15,16}$. All conditions described in this study are rare.

Hypertrichosis can be classified as being associated with other symptoms, or as an isolated feature, but there are only a few examples of hypertrichosis as a cardinal symptom ${ }^{17}$. The majority of diseases express hypertrichosis as a component of complex syndromes ${ }^{18}$, as shown in this study. Another classification is based on the localization hypertrichosis; however, the literature is not always clear enough to discern between localized and generalized hypertrichosis.

Head and neck features were the most affected category, identified in more than two-thirds of the disturbances; this includes abnormalities in the head, face, ears, eyes, nose, mouth, neck, and teeth, which reveal the importance of a thorough physical exam. Teeth abnormalities were identified in 32.23\% of genetic entities. Dental anomalies are excellent dysmorphic markers and may help in syndrome diagnosis ${ }^{12,19}$.

Skeletal involvement was identified in $78.51 \%$ of disturbances. Genetic skeletal disorders account for most human skeletal dysplasia; however, the genotype-phenotype correlations remain an important challenge ${ }^{20}$. Mutations in the same gene may be associated with heterogeneous phenotypes, as the same phenotype can be caused by mutations in several genes, such as Coffin-Siris, which has a wide genetic heterogeneity ${ }^{20}$.

The nervous system was affected in $73.55 \%$ of the genetic entities. ID is a prominent feature observed in $52.06 \%$ of cases, usually identified early in childhood, due to developmental delay $^{7}$. Given the greater clinical severity of the disease, its incidence is much higher than the worldwide prevalence, estimated at $1 \%$ of the general population ${ }^{21}$. ID is diagnosed by IQ testing; however, its severity (i.e., mild, moderate, severe, and profound) can be highly variable, even in the same disorder, given the wide heterogeneous phenotype of genetic diseases ${ }^{21}$.

Another major concern is the association between hypertrichosis and cancer development, observed in $8.26 \%$ of cases (Table 2). In this context, different genes are associated, the main inheritance pattern observed is autosomal dominant, and the prognosis is usually poor. No correlation was found between the genetic entity and a unique type of malignancy, as 
Chart 1. Genetic syndromes associated with hypertrichosis.

\begin{tabular}{|c|c|}
\hline \multicolumn{2}{|c|}{ Syndromes } \\
\hline Achalasia-Microcephaly & Dental Anomalies And Short Stature \\
\hline Adducted Thumbs Syndrome & Desanto-Shinawi Syndrome \\
\hline $\begin{array}{l}\text { Agenesis of corpus callosum, cardiac, } \\
\text { ocular, and genital syndrome }\end{array}$ & Developmental and Epileptic Encephalopathy 57 \\
\hline Alazami-Yuan Syndrome & $\begin{array}{l}\text { Developmental and Epileptic Encephalopathy } 85 \text { With or } \\
\text { Without Midline Brain Defects }\end{array}$ \\
\hline $\begin{array}{l}\text { Amaurosis Congenita, Cone-Rod Type, } \\
\text { With Congenital Hypertrichosis }\end{array}$ & $\begin{array}{l}\text { Diabetes Mellitus, Insulin Resistant, With Acanthoses } \\
\text { Nigricans Type A }\end{array}$ \\
\hline $\begin{array}{c}\text { Anemia, Congenital Hypoplastic, With Multiple Congenital } \\
\text { Anomalies/Mental Retardation Syndrome }\end{array}$ & Diarrhea, chronic, with villous atrophy \\
\hline Barber-Say Syndrome & Distichiais, Tristichiasis \\
\hline Becker Nevus Syndrome & Donohue Syndrome \\
\hline Beckwith-Wiedemann Syndrome & Dysraphism \\
\hline Bloom Syndrome & Dyssegmental Dysplasia, Rolland-Desbuquois Type \\
\hline Bohring-Opitz Syndrome & $\begin{array}{l}\text { Ectodermal Dysplasia 14, Hair/Tooth Type } \\
\text { with or Without Hypohidrosis }\end{array}$ \\
\hline Cahmr Syndrome & Ehlers-Danlos Syndrome, Dermatosparaxis Type \\
\hline Cantu Syndrome & Erythroderma, Ichthyosiform, Congenital, Reticular \\
\hline $\begin{array}{c}\text { Cerebellar Ataxia, Mental Retardation, And Dysequilibrium } \\
\text { Syndrome } 2\end{array}$ & Erythrokeratodermia Variabilis Et Progressiva 2 \\
\hline Cerebellar, Ocular, Craniofacial, And Genital Syndrome & $\begin{array}{l}\text { Facial Dysmorphism, Hypertrichosis, Epilepsy, Intellectual/ } \\
\text { Developmental Delay, And Gingival Overgrowth Syndrome }\end{array}$ \\
\hline $\begin{array}{c}\text { Cerebral Malformation, Seizures, Hypertrichosis, } \\
\text { And Overlapping Fingers }\end{array}$ & Facial Hypertrichosis \\
\hline Cerebrooculofacioskeletal Syndrome 1 & $\begin{array}{l}\text { Fibromatosis, Gingival, With Hypertrichosis And Mental } \\
\text { Retardation }\end{array}$ \\
\hline Cervical Hypertrichosis with Underlying Kyphoscoliosis & Filippi Syndrome \\
\hline Cervical Hypertrichosis, Anterior Cervical & Floating-Harbor Syndrome \\
\hline $\begin{array}{c}\text { Cervical Hypertrichosis, Congenital Anterior Cervical, with } \\
\text { Peripheral Sensory and Motor Neuropathy }\end{array}$ & Fontaine Progeroid Syndrome \\
\hline Chromosome 17q12 Deletion Syndrome & Frontometaphyseal Dysplasia 1 e 2 \\
\hline Chromosome 17q21.31 Duplication Syndrome & GM-1 - Gangliosidosis type I \\
\hline Coffin-Siris Syndrome 1, 2, 3, 4, 8,9 & Hairy Ears; Hairy Ears, Y-Linked \\
\hline Congenital Disorder Of Glycosylation laa, lq e lle & Hairy Elbows \\
\hline Cornelia De Lange Syndrome 1, 3, 4 & Hairy Palms and Soles \\
\hline Corpus Callosum, Agenesis Of, With Abnormal Genitalia & Hajdu-Cheney Syndrome \\
\hline Cousin Syndrome & Hennekam Lymphangiectasia-Lymphedema Syndrome 1 \\
\hline Craniorhiny & $\begin{array}{l}\text { Histiocytosis-Lymphadenopathy Plus Syndrome } \\
\text { H Syndrome, Rosai-Dorfman Disease, Familial }\end{array}$ \\
\hline Crouzon Syndrome & $\begin{array}{l}\text { Hydronephrosis Congenital, With Cleft Palate, } \\
\text { Characteristic Facies, Hypotonia, Mental Retardation }\end{array}$ \\
\hline Curry-Jones Syndrome & $\begin{array}{c}\text { Hypertrichosis lanuginosa; congenital; with/without } \\
\text { gingival hyperplasia; Ambras }\end{array}$ \\
\hline
\end{tabular}




\begin{tabular}{|c|c|}
\hline \multicolumn{2}{|c|}{ Syndromes } \\
\hline Hypomelanosis of Ito & $\begin{array}{l}\text { Neurodevelopmental Disorder With Progressive } \\
\text { Microcephaly, Spasticity, And Brain Anomalies }\end{array}$ \\
\hline $\begin{array}{l}\text { Intellectual developmental disorder with cardiac defects } \\
\text { and dysmorphic facies }\end{array}$ & Nevoid Hypertrichosis \\
\hline Imagawa-Matsumoto Syndrome & Oliver-Mcfarlane Syndrome \\
\hline Immunodeficiency 49 & Perching Syndrome \\
\hline Joubert Syndrome 10 & Polythelia Pilosa \\
\hline Kabuki Syndrome 2 & Pontocerebellar Hypoplasia Type 8 \\
\hline Leigh Syndrome & $\begin{array}{c}\text { Porphyria Cutanea Tarda I, li,Porphyria, Congenital } \\
\text { Erythropoietic Variegate Porphyria }\end{array}$ \\
\hline Lethal Short-Limb Skeletal Dysplasia, Al Gazali Type & Primary Multifocal Localized Hypertrichosis \\
\hline Leukodystrophy, Hypomyelinating, 17 & Ramon Syndrome \\
\hline Liang-Wang Syndrome & Rubinstein-Taybi Syndrome I, li \\
\hline Lichtenstein Syndrome & Sandestig-Stefanova Syndrome \\
\hline Light Fixation Seizure Syndrome & Schinzel-Giedion Midface Retraction Syndrome \\
\hline $\begin{array}{c}\text { Lipodystrophy, Congenital Generalized, Type } 2 \\
\text { Berardinelli-Seip Syndrome }\end{array}$ & Schwartz-Jampel Syndrome, Type 1 \\
\hline Lissencephaly 7 With Cerebellar Hypoplasia & Seckel Syndrome 9 \\
\hline Lymphedema-Hypoparathyroidism Syndrome & Segmental Odontomaxillary Dysplasia \\
\hline $\begin{array}{l}\text { Mandibulofacial Dysostosis With Macroblepharon And } \\
\text { Macrostomia }\end{array}$ & Sialuria \\
\hline Mannosidosis, Alpha B, Lysosomal & Spastic Paraplegia 53, Autossomal Recessive \\
\hline Marshall-Smith Syndrome & Specific Granule Deficiency 2 \\
\hline Meester-Loeys syndrome & $\begin{array}{c}\text { Spinocerebellar Ataxia 42, Early-Onset, Severe, With } \\
\text { Neurodevelopmental Deficits }\end{array}$ \\
\hline Melanocytic Nevus Syndrome & Spinocerebellar Ataxia, Autosomal Recessive 20 \\
\hline Mental Retardation, Autosomal Dominant 57 & Spondyloepimetaphyseal Dysplasia, Genevieve Type \\
\hline Mental Retardation, Autosomal Recessive 35 & Stocco Dos Santos X-Linked Mental Retardation Syndrome \\
\hline $\begin{array}{l}\text { Mental Retardation, Microcephaly, Epilepsy, } \\
\text { And Coarse Face }\end{array}$ & Sweeney-Cox Syndrome \\
\hline $\begin{array}{l}\text { Mental Retardation, X-Linked 99, } \\
\text { Syndromic, Female-Restricted }\end{array}$ & Tenorio Syndrome \\
\hline $\begin{array}{l}\text { Mental Retardation, X-Linked, Syndromic, } \\
\text { Chudley-Schwartz Type }\end{array}$ & Trichohepatoneurodevelopmental Syndrome \\
\hline $\begin{array}{l}\text { Mental Retardation, X-Linked, } \\
\text { Syndromic, Nascimento Type }\end{array}$ & Trichomegaly \\
\hline Michelin Tire Baby Syndrome & Vissers-Bodmer Syndrome \\
\hline Mitochondrial Complex I Deficiency, Nuclear Type 23 & Warburg Micro Syndrome \\
\hline Mucopolysaccharidosis, Type li, liic, liid, Vii & Wiedemann-Steiner Syndrome \\
\hline $\begin{array}{l}\text { Mullerian Derivatives, Persistence Of, With } \\
\text { Lymphangiectasia And Postaxial Polydactyly }\end{array}$ & Zimmermann-Laband Syndrome 1 \\
\hline Multicentric Osteolysis, Nodulosis, And Arthropathy & \\
\hline
\end{tabular}


one condition can be associated with several types of malignancies, but some may occur more often than others. For example, melanocytic nevus syndrome is associated with melanoma,

Table 1. Clinical features of hypertrichosis associated genetic syndromes.

\begin{tabular}{l|c} 
Head and neck & $\begin{array}{c}\text { Syndromes } \\
\mathrm{n}(\%)\end{array}$ \\
\hline Skeletal & $97(80.16)$ \\
\hline Nervous system & $95(78.51)$ \\
\hline Intellectual disability & $89(73.55)$ \\
\hline Autosomal recessive & $63(52.06)$ \\
\hline Abdominal & $54(44.62)$ \\
\hline Genitourinary & $52(42.97)$ \\
\hline Autosomal dominant & $48(39.66)$ \\
\hline Cardiovascular & $44(36.36)$ \\
\hline Dental anomalies & $39(32.23)$ \\
\hline Respiratory & $39(32.23)$ \\
\hline Other or unknown inheritance pattern* & $31(25.61)$ \\
\hline Early death (until childhood) & $25(20.66)$ \\
\hline Endocrine & $22(18.18)$ \\
\hline Neoplasia & $17(14.04)$ \\
\hline
\end{tabular}

*X-linked, Y-linked, somatic mosaicism, somatic mutation, and isolated cases. and Beckwith-Wiedemann is associated with Wilms tumor and hepatoblastoma ${ }^{22,23}$. Nevertheless, Bloom syndrome and Schinzel-Giedion syndrome are associated with multiple malignancies ${ }^{24,25}$. In other genetic diseases, such as the Bohring-Opitz syndrome and Rubinstein-Taybi syndrome, tumor predisposition has been observed in many case reports, but the risk cannot be established or fully dismissed because epidemiologic studies have not been conducted to demonstrate an increased risk of developing cancer ${ }^{26,27}$.

Hypertrichosis is not caused by androgens but is often confused with hirsutism, which is usually associated with hyperandrogenism. In this study, 17 conditions were associated with endocrinopathies. The most common abnormalities were diabetes mellitus, insulin resistance, and thyroid dysfunction (hypothyroidism and thyroid lymphangiectasis). Diabetes mellitus, insulin resistance, acanthosis nigricans type $\mathrm{A}$, and Donohue syndrome are caused by a mutation in the insulin receptor gene (INSR) and are associated with insulin resistance and hyperinsulinemia ${ }^{28,29}$. Another example is the Berardinelli-Seip syndrome, which is associated with polycystic ovary disease, diabetes mellitus, and the Beckwith-Wiedemann syndrome, which is associated with adrenocortical cytomegaly and pituitary hyperplasia ${ }^{23,30}$. However, the Donohue syndrome, BerardinelliSeip syndrome, and Beckwith-Wiedemann syndrome are the major causes of hypertrichosis in the literature $e^{1,2,18,23}$. One probable reason why these genetic conditions are classified as

Table 2. Genetic disturbances with hypertrichosis associated with neoplasia.

\begin{tabular}{|c|c|c|c|c|}
\hline Syndrome & OMIM & Inheritance & Gene & Chromosome \\
\hline Beckwith-Wiedemann & 130650 & $A D$ & $\begin{array}{l}\text { H19; ICR1; } \\
\text { KCNQ10T1; } \\
\text { CDKN1C }\end{array}$ & $\begin{array}{l}11 \mathrm{p} 15.5 \\
11 \mathrm{p} 15.4\end{array}$ \\
\hline Bloom & 210900 & $A R$ & RECQL3 & $15 q 26.1$ \\
\hline Bohring-Opitz & 605039 & $A D$ & ASXL1 & $20 q 11.21$ \\
\hline Curry-Jones & 611707 & Somatic mosaicism & SMO & $7 q 32.1$ \\
\hline Donohue & 246200 & $A R$ & INSR & $19 p 13.2$ \\
\hline Melanocytic nevus & 137550 & Somatic mutation & NRAS & $1 p 13.2$ \\
\hline Polythelia pilosa & - & - & - & - \\
\hline $\begin{array}{l}\text { Porphyria } \\
\text { Cutanea tarda I, II } \\
\text { Congenital erythropoietic } \\
\text { porphyria } \\
\text { Variegate porphyria }\end{array}$ & $\begin{array}{l}176090 \\
176100 \\
263700 \\
176200\end{array}$ & $\begin{array}{c}A D-A R \\
A R \\
A D\end{array}$ & $\begin{array}{l}\text { UROD } \\
\text { UROS } \\
\text { PPOX }\end{array}$ & $\begin{array}{c}1 p 34.1 \\
10 q 26.2 \\
1 q 23.3\end{array}$ \\
\hline Rubinstein-Taybi I, II & $\begin{array}{l}180849 \\
613684\end{array}$ & $\begin{array}{l}A D \\
A D\end{array}$ & $\begin{array}{l}\text { CREBBP } \\
\text { EP300 }\end{array}$ & $\begin{array}{l}16 p 13.3 \\
22 q 13.2\end{array}$ \\
\hline $\begin{array}{l}\text { Schinzel-Giedion midface } \\
\text { retraction syndrome }\end{array}$ & 269150 & $A D$ & SETBP1 & $18 q 12.3$ \\
\hline
\end{tabular}

AD: autosomal dominant; AR: autosomal recessive; OMIM: Online Mendelian Inheritance in Man. 
hypertrichosis is that hyperandrogenism may aggravate the problem, as hypertrichosis has also been described in adult males, not only in androgen-dependent areas ${ }^{1,2,18}$.

Hypertrichosis can cause significant emotional distress for affected patients and their families ${ }^{1,18}$. Patients may experience difficulty in accessing the qualified health system, as the clinical characteristics are heterogeneous and can lead to diagnosis delays ${ }^{15}$. Early diagnosis of these conditions helps guide early intervention, screening, and genetic counseling of patients and their family members. The development of clinical protocols helps health professionals, patients, and families to make decisions regarding the most appropriate alternatives for their healthcare.

There is a limitation in the interpretation of data from case reports, with a small number of patients, an inherent characteristic of rare disease studies. The literature is not always clear enough to elucidate the type of hair disorder, whether hypertrichosis or hirsutism. In fact, it is common for both terms to be used in case reports of the same genetic disorder. It was imperative to deepen the knowledge to perform the necessary discernment to conduct the work and exclude what was not the object of investigation of the study.

\section{CONCLUSIONS}

This study shows that hypertrichosis may be more common than estimated, especially when we consider it to be a phenotype of several diseases. The research also suggested that cutaneous manifestations may also hide an underlying disease that requires investigation. Multiple organ systems can be affected, and the study highlights the most affected ones. These aspects reinforce the need for further studies to support protocols for public organizations and policies, facilitate decision-making, and promote ongoing health training for the management of hypertrichosis and its underlying potential disorders.

\section{ACKNOWLEDGMENT}

The authors thank the Minas Gerais State Research Foundation - Fapemig, Brazil and National Council for Scientific and Technological Development - CNPq, Brazil.

\section{AUTHORS' CONTRIBUTIONS}

VFC: Conceptualization, Data curation, Formal analysis, Writing - original draft, Writing - review and editing. MCB: Conceptualization, Data curation, Formal analysis, Writing original draft. DRBM: Conceptualization, Writing - review and editing. MJBA: Formal analysis, Writing - review and editing. PRB: Formal analysis, Writing - review and editing. HMJ: Conceptualization, Data curation, Formal analysis, Writing - review and editing.

\section{REFERENCES}

1. Wendelin DS, Pope DN, Mallory SB. Hypertrichosis. J Am Acad Dermatol. 2003;48(2):161-79;quiz180-1. https://doi. org/10.1067/mjd.2003.100

2. Garcia-Cruz D, Figuera LE, Cantu JM. Inherited hypertrichoses. Clin Genet. 2002;61(5):321-9. https://doi.org/10.1034/j.13990004.2002.610501.x

3. Polizzi A, Pavone P, Ciancio E, La Rosa C, Sorge G, Ruggieri M. Hypertrichosis cubiti (hairy elbow syndrome): a clue to a malformation syndrome. J Pediatr Endocrinol Metab. 2005;18(10):1019-25. https://doi.org/10.1515/jpem.2005.18.10.1019

4. Stenn KS, Paus R. Controls of hair follicle cycling. Physiol Rev. 2001;81(1):449-94. https://doi.org/10.1152/ physrev.2001.81.1.449

5. Hohl A, Ronsoni MF, Oliveira Md. Hirsutism: diagnosis and treatment. Arq Bras Endocrinol Metabol. 2014;58(2):97-107. https://doi.org/10.1590/0004-2730000002923

6. Rosenfield RL. Clinical practice. Hirsutism. N Engl J Med. 2005;353(24):2578-88. https://doi.org/10.1056/NEJMcp033496

7. Pezzani L, Milani D, Tadini G. Intellectual disability: when the hypertrichosis is a clue. J Pediatr Genet. 2015;4(3):154-8. https://doi.org/10.1055/s-0035-1564442

8. Harari S. Why we should care about ultra-rare disease. Eur Respir Rev. 2016;25(140):101-3. https://doi. org/10.1183/16000617.0017-2016
9. Wästfelt M, Fadeel B, Henter Jl. A journey of hope: lessons learned from studies on rare diseases and orphan drugs. J Intern Med. 2006;260(1):1-10. https://doi.org/10.1111//.1365-2796.2006.01666.x

10. Martelli DRB, Martelli Júnior $\mathrm{H}$. Undiagnosed and rare diseases: current challenges, perspectives and contribution of oral cavity examination. Oral Surg Oral Med Oral Pathol Oral Radiol. 2020;130(2):227-8. https://doi.org/10.1016/j.0000.2020.04.011

11. Maranda EL, Fipps D, Danek D, Taneja R, Marsh AM, Jimenez JJ. Dermatologic marvels-hypertrichosis. JAMA Dermatol. 2016;152(5):552. https://doi.org/10.1001/jamadermatol.2015.4846

12. Bondeson J, Miles AE. Julia Pastrana, the nondescript: an example of congenital, generalized hypertrichosis terminalis with gingival hyperplasia. Am J Med Genet. 1993;47(2):198212. https://doi.org/10.1002/ajmg.1320470213

13. Hartley T, Balci TB, Rojas SK, Eaton A, Canada CR, Dyment $D A$, et al. The unsolved rare genetic disease atlas? An analysis of the unexplained phenotypic descriptions in $\mathrm{OMIM}^{\circledR}$. Am J Med Genet C Semin Med Genet. 2018;178(4):458-63. https:// doi.org/10.1002/ajmg.c.31662

14. Richter T, Nestler-Parr S, Babela R, Khan ZM, Tesoro T, Molsen $E$, et al. Rare Disease Terminology and Definitions-A Systematic Global Review: Report of the ISPOR Rare Disease Special Interest Group. Value Health. 2015;18(6):906-14. https://doi. org/10.1016/j.jval.2015.05.008 
15. Brazil. Ministério da Saúde. Doenças raras. Brasília: Ministério da Saúde; 2020. [cited on Fev. 2, 2021]. Available from: https:// uww.gov.br/saude/pt-br/assuntos/saude-de-a-a-z/d/doencas-raras

16. Martelli Júnior H. In reply to: Alawi F. "Using rare diseases as teaching models to increase awareness". Oral Surg Oral Med Oral Pathol Oral Radiol. 2019;128(6):690-1. https://doi. org/10.1016/j.0000.2019.07.002

17. De Raeve L, Keymolen K. Congenital hypertrichosis lanuginosa in a father and son. Arch Dermatol. 2011;147(6):746-7. https:// doi.org/10.1001/archdermatol.2011.137

18. Pavone $P$, Praticò $A D$, Falsaperla R, Ruggieri $M$, Zollino $M$, Corsello $G$, et al. Congenital generalized hypertrichosis: the skin as a clue to complex malformation syndromes. Ital J Pediatr. 2015;41:55. https://doi.org/10.1186/s13052-015-0161-3

19. Bloch-Zupan $A$. When neuropediatrics meets odontology. Neuropediatrics. 2007;38(2):57-8. https://doi. org/10.1055/s-2007-985135

20. Geister KA, Camper SA. Advances in skeletal dysplasia genetics. Annu Rev Genomics Hum Genet. 2015;16:199-227. https:// doi.org/10.1146/annurev-genom-090314-045904

21. Vissers LE, Gilissen C, Veltman JA. Genetic studies in intellectual disability and related disorders. Nat Rev Genet. 2016;17(1):918. https://doi.org/10.1038/nrg3999

22. Kinsler VA, Thomas AC, Ishida M, Bulstrode NW, Loughlin $S$, Hing $S$, et al. Multiple congenital melanocytic nevi and neurocutaneous melanosis are caused by postzygotic mutations in codon 61 of NRAS. J Invest Dermatol. 2013;133(9):222936. https://doi.org/10.1038/jid.2013.70
23. Zollino M, Orteschi D, Marangi G, De Crescenzo A, Pecile V, Riccio $A$, et al. A case of Beckwith-Wiedemann syndrome caused by a cryptic 11 p15 deletion encompassing the centromeric imprinted domain of the BWS locus. J Med Genet. 2010;47(6):429-32. https://doi.org/10.1136/jmg.2009.071142

24. Ellis NA, German J. Molecular genetics of Bloom's syndrome. Hum Mol Genet. 1996;5Spec No:1457-63. https://doi. org/10.1093/hmg/5.supplement_1.1457

25. Hoischen A, van Bon BW, Gilissen C, Arts P, van Lier B, Steehouwer $M$, et al. De novo mutations of SETBP1 cause Schinzel-Giedion syndrome. Nat Genet. 2010;42(6):483-5. https://doi.org/10.1038/ng.581

26. Hennekam RCM. Rubinstein-Taybi syndrome. Eur J Hum Genet. 2006;14(9):981-5. https://doi.org/10.1038/sj.ejhg.5201594

27. Hoischen A, van Bon BW, Rodríguez-Santiago B, Gilissen C, Vissers LE, Vries $P$, et al. De novo nonsense mutations in ASXL1 cause Bohring-Opitz syndrome. Nat Genet. 2011;43(8):72931. https://doi.org/10.1038/ng.868

28. Mariani S, Pedone A, Meschi F, di Natale B, Caputo R, Broggi $U$, et al. Insulin resistance in a child with Acanthosis nigricans type A. Acta Paediatr Scand. 1982;71(4):667-70. https://doi. org/10.1111/j.1651-2227.1982.tb09496.x

29. Cantani A, Ziruolo MG, Tacconi ML. A rare polydysmorphic syndrome: leprechaunism - review of forty-nine cases reported in the literature. Ann Genet. 1987;30(4):221-7. PMID: 3322162

30. Garg A. Acquired and inherited lipodystrophies. N Engl J Med. 2004;350(12):1220-34. https://doi.org/10.1056/NEJMra025261 